\title{
Author Correction: Nanoscale movements of cellulose microfibrils in primary cell walls
}

Tian Zhang, Dimitrios Vavylonis, Daniel M. Durachko and Daniel J. Cosgrove

Correction to: Nature Plants https://doi.org/10.1038/nplants.2017.56, published online 28 April 2017.

In the Supplementary Information originally published for this Article, we would like to clarify Extended Data Figure 2a where the first and second extension cycles were identified, with each cycle encompassing two loading curves for a total of four loading curves. At least one reader interpreted the graphs to mean two loading curves and two unloading curves, which is not the case. Thus, Extended Data Figure $2 \mathrm{a}$ and its legend have been amended for greater clarity. The data have not changed, and the original results and conclusions are unaffected. The amended Supplementary Information file is supplied with this correction notice.
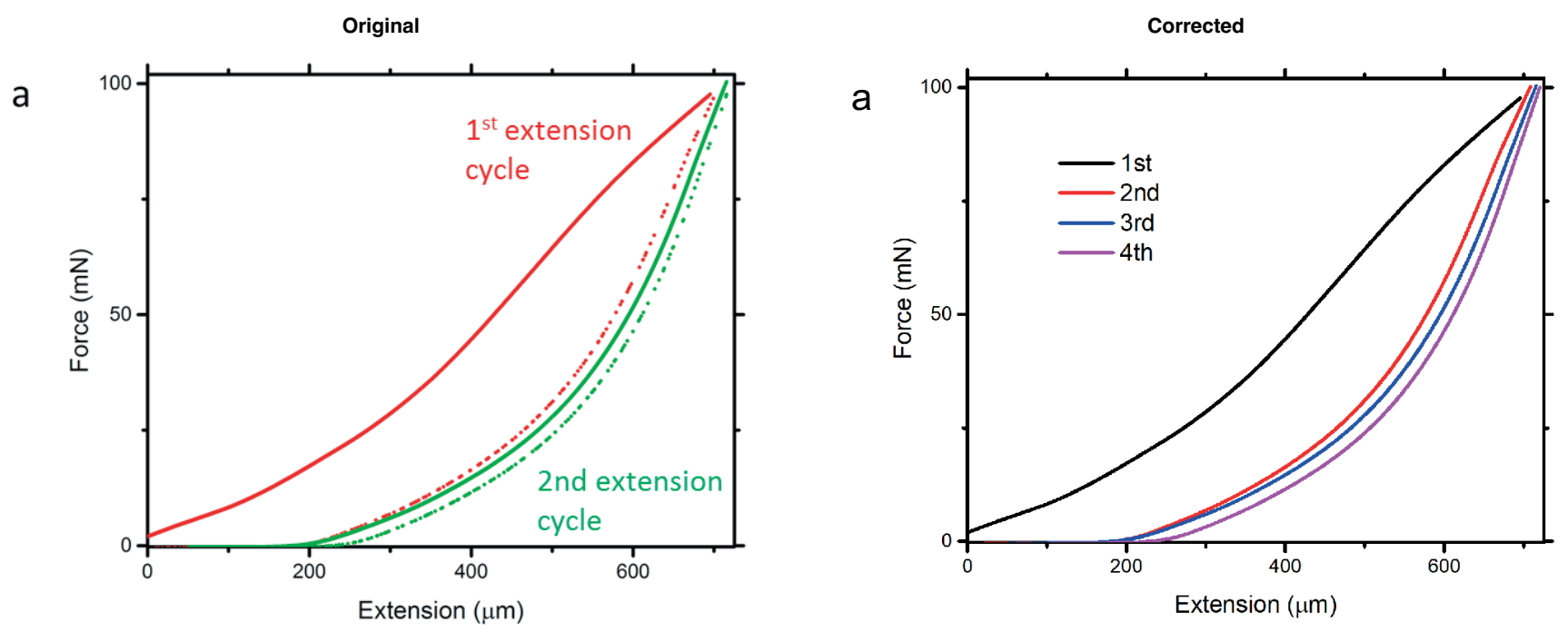

Extended Data Fig. 2. | Corrected.

\section{Additional information}

Supplementary information is available for this paper at https://doi.org/10.1038/s41477-020-00821-w.

Published online: 26 November 2020

https://doi.org/10.1038/s41477-020-00821-w

(C) The Author(s), under exclusive licence to Springer Nature Limited 2020 